\title{
Physiological and biochemical responses of seedlings of six contrasting barley (Hordeum vulgare L.) cultivars grown under salt-stressed conditions
}

\author{
Jitendra Kumar Sharma \\ Centre for Biotechnology, Maharshi Dayanand University, Rohtak-124001 (Haryana), India \\ Monika Sihmar \\ Centre for Biotechnology, Maharshi Dayanand University, Rohtak-124001 (Haryana), India \\ Anita Rani Santal \\ Department of Microbiology, Maharshi Dayanand University, Rohtak-124001 (Haryana), India \\ Nater Pal Singh* \\ Centre for Biotechnology, Maharshi Dayanand University, Rohtak-124001 ( Haryana), India \\ *Corresponding author. Email: npsingh.cbt@mdurohtak.ac.in
}

\section{Article Info}

https://doi.org/10.31018/ jans.v13i3.2863

Received: July 15, 2021

Revised: August 29, 2021

Accepted: September 3, 2021

\section{How to Cite}

Sharma, J. K. et al. (2021). Physiological and biochemical responses of seedlings of six contrasting barley (Hordeum vulgare L.) cultivars grown under salt-stressed conditions. Journal of Applied and Natural Science, 13(3), 1020 - 1031. https:// doi.org/10.31018/jans.v13i3.2863

\begin{abstract}
Salinity stress affects plant growth and development and underlying metabolisms. To mitigate the effects of the stress, plants responded by changing their physiological and biochemical activities and withstand the stress. The present study aimed to determine barley's (Hordeum vulgare L.) physiological and biochemical response to salinity stress conditions for 7 days and 14 days. Six barley cultivars (Alfa93, DWRB73, DL88, NB1, NB3, NDB1173) were grown under controlled conditions, and different level of salinity stress was applied. In addition, seedling growth, physiological and biochemical parameters, plant leaves RWC, and electrolyte leakage were analyzed. The overall seedling growth, RWC, and electrolyte leakage in salt susceptible lines Alfa93 and DWRB73 were low than the salt-tolerant barley lines (DL88, NB1, NB3, and NDB1173). Electrolyte leakage was 26.0 and $20.6 \%$ in Alfa93 and DWRB73, whereas it was 17.6, 14.6, 15.3, and 10.4\% in DL88, NB1, NB3, and NDB1173, respectively at $300 \mathrm{mM}$ salinity stress. The loss of photosynthetic pigments under salt stress was high in susceptible lines, salinity treated $(300 \mathrm{mM} \mathrm{NaCl})$ Alfa93 plants exhibit $49.5 \%$ and $59.5 \%$ of Chl-a than control plants after 7 and 14 days of treatment, respectively. However, at $300 \mathrm{mM}$ stress level, NB1 (ST) showed less Chl-a loss after 7 days, whereas NDB1173 showed less reduction in Chl-a after 14 days. Antioxidant enzymes such as SOD, POX, CAT, and APX activities in susceptible line Alfa93 and DWRB73 were lower than tolerant lines. PCA analysis demonstrated a positive correlation between antioxidant enzyme activities and genotypes under salinity stress. PCA analysis described DL88 as the most tolerant, and DWRB73 was the most salt susceptible genotype among the studied barley genotypes. The present findings suggest that barley cultivars' physiological and biochemical activities under salinity stress conditions may be used to screen salt-tolerant crops.
\end{abstract}

Keywords: Antioxidant enzymes, Barley, Chlorophyll, Eelectrolyte leakage, RWC, Salt stress.

\section{INTRODUCTION}

Barley is grown worldwide for various purposes, such as human consumption, feed for livestock, and brewing and malting (Noreen et al., 2021). Barley ranked fourth among cereal crops in total world production after wheat, rice, and corn (Naeem et al., 2021). It is cultivated in various environmental conditions, such as subarctic to sub-tropical (Bera et al. 2018).

Salt stress is a major ecological as well as an agro- nomic problem all over the world.

Around 6.74 million ha of land in India is affected by salinity, and an estimation of $10 \%$ rise every year, around $50 \%$ of the total arable land by 2050 (Kumar and Sharma 2020).

Not only has the natural salinity, but the salinization by human activity also becomes a serious threat to agricultural production (Ortiz and Jin 2021). Under high salt stress condition, plants uptake high concentration of soluble salt which resists the water movement inside 
the root and cause osmotic stress. The osmotic stress alters the membrane stability and influences the absorption of high concentrations of salt inside cells. As a result, high ions compete with the uptake of essential nutrients and cause nutrition deficiency (Arif et al. 2020; Moradi et al. 2021).

Due to the excessive salts in the soil decrease its osmotic potentials and the water availability to the roots. It also results in considerable ROS accumulation in roots and leaves (Tanou et al., 2009; Xie et al., 2011). Antioxidant enzymes provide tolerance to the plants against various stresses. Superoxide dismutase initiates the first vital step against oxidative stress in plants by converting superoxide $\left(\mathrm{O}^{{ }^{-}}\right)$to hydrogen peroxide $\left(\mathrm{H}_{2} \mathrm{O}_{2}\right)$, and further catalase (CAT), guaiacol peroxidase (POD), and ascorbate peroxidase (APX) catalyze the hydrogen peroxide into water and oxygen (Zhu et al., 2020).

Plants harness the light from the photosynthetically active radiation (PAR) region with the help of pigments in the green part. Three pigments, specifically chlorophylla (Chl-a), chlorophyll-b (Chl-b), and the carotenoids (CRT), are actively involved in photosynthesis. The amount of these pigments in the plants rules the photosynthetic potential and determines its efficiency in utilizing PAR for the biosynthesis process (Kume et al. 2018). Therefore, the physiological status of plants is directly related to these pigment concentrations, and changes in these affect the plants' growth and development.

Barley can be used as a model crop to study the mechanism of salinity tolerance because it is the most salinity tolerant crop among other cereal crops. Physiological changes in the plants under salinity stress give insight into the salinity response of plants. Therefore, the present study was carried out to explain physiological and biochemical characteristics such as chlorophyll content, carotenoid content, electrolyte leakage, antioxidative enzymes in providing salinity tolerance to the plants.

\section{MATERIALS AND METHODS}

\section{Plant materials and experimental conditions}

Barley seeds were procured from the Indian Institute of Wheat and Barley Research (IIWBR), Karnal, India. Seeds were screened for salt tolerance, and six cultivars were chosen for study, salt-tolerant (ST) lines DL 88, NB 1, NB 3, NDB 1173, and salt-sensitive (SS) lines Alfa 93 and DWRB 73. Seeds were surface sterilized using $0.1 \% \mathrm{HgCl}_{2}$ solution and then placed on wet filter paper for germination at $25^{\circ}$ in the growth chamber at Centre for Biotechnology, M D University, Rohtak, India). After germination, seeds were transferred to plastic pots filled with sand (thoroughly washed with distilled water and autoclaved). Seedlings were supplied with half-strength Hoagland solution (Jones, 1982), and the growth conditions provided were $16 \mathrm{hr}$ light and $8 \mathrm{hr}$ dark cycle, day temperature $25^{\circ} \mathrm{C}$ with $60 \%$ relative humidity and night temperature was $18^{\circ} \mathrm{C}$. When seedlings were attained two-leaf stage, salt stresses were introduced gradually (25 mM morning and $25 \mathrm{mM}$ evening up to the desirable levels) to avoid osmotic shock. Plant growth conditions and salinity stress treatment followed Elsawy et al.'s methods (2018) with few modifications. Salinity levels include control $(0 \mathrm{mM}), 100$, 200 , and $300 \mathrm{mM} \mathrm{NaCl}$ solution in half-strength Hoagland solution. The plant samples were collected after 7 days of salt treatment and 14 days of salt treatment.

\section{Relative water Content}

The leaf's relative water content (RWC) was assessed just after collecting plants, leaf fresh weight (FW) was taken without delay, and then leaves were rehydrated by floating them in distilled water at room temperature for 4 hours. After rehydration, leaf turgid weight (TW) was measured, and then leaves were kept in an oven at $60^{\circ} \mathrm{C}$ for 48 hours. After 48 hours, the dry weight (DW) of leaves was measured, leaf RWC was calculated using the formula (Barrs and Weatherley, 1962).

$$
\text { RWC }(\%)=\left[\frac{\text { FW-DW }}{\text { TW-DW }}\right] \times 100
$$

\section{Study of relative electrolyte leakage (REL)}

Electrolyte leakage of barley leaves was analyzed according to Lakra et al. (2015). Leaf samples were collected from the control, and salinity-stressed plants, washed gently with distilled water to eliminate any surface adhering ions. About $100 \mathrm{mg}$ leaf tissue was weighed and immediately dipped into $20 \mathrm{ml}$ milli-Q water, incubating the sample at $60^{\circ}$ for 2 hours. After that, samples were cooled to room temperature, and the electrical conductivity (E1) of the solution was measured using a conductivity meter (Okaton, USA). Total conductivity (E2) was determined by autoclaving the solution with the sample at $121^{\circ}$ for 15 minutes. Samples were cooled to room temperature, and the conductivity of the solution was measured. Relative electrical conductivity was measured using the formula:

Relative electrolyte leakage \% $(\mathrm{REL} \%)=(\mathrm{E} 1 / \mathrm{E} 2) \times 100$

$$
\text { ......Eq.2 }
$$

\section{Determination of photosynthetic pigments}

Chlorophyll content was extracted using the method described by Minocha et al. (2009) with few modifications. Approx $50 \mathrm{mg}$ leaves from all varieties were taken and placed in $8 \mathrm{ml} \mathrm{DMSO}$ and incubated at $60^{\circ} \mathrm{C}$ for 4 hours in the dark. The pigment concentration was measured by taking absorbance at 480, 649, and $665 \mathrm{~nm}$ using a UV/ vis spectrophotometer (Genetix, Spectro-8). The content of chlorophyll-a (Chl-a), Chlorophyll-b (Chl-b), and carotenoids (CRT) were calculated according to the formula described by Wellburn (1994). 


\section{Antioxidant enzyme activity assay}

Antioxidant enzyme activity assay was done according to the method described by Lakra et al. (2015). About $100 \mathrm{mg}$ fresh leaves were collected from the control and salt-stressed plants and freeze in liquid nitrogen. Leaves were homogenized in ice-cold $50 \mathrm{mM}$ potassium phosphate buffer $(\mathrm{pH} 7.5)$ consists of $2 \mathrm{mM}$ EDTA and $0.1 \mathrm{mM}$ PMSF. Ascorbate $(2 \mathrm{mM})$ was additionally added to the homogenizing buffer for ascorbate peroxidase (APX). The homogenates were centrifuged at $12000 \times \mathrm{g}$ for 10 minutes at $4{ }^{\circ} \mathrm{C}$. The supernatant was collected in fresh microcentrifuge tubes and used for enzyme assay. The activity of superoxide dismutase (SOD) was measured according to the method described by Dhindsa et al. (1981), the ability of the enzyme to inhibit the photochemical reduction of nitroblue tetrazolium (NBT). The guaiacol peroxidase (POD) activity was assayed according to the method of Chance and Maehly (1955), based on the ability of the enzyme to convert guaiacol to tetraguaiacol $(\varepsilon=26.6$ $\mathrm{mM}^{-1} \mathrm{~cm}^{-1}$ ). The catalase (CAT) activity was determined according to the method of Chance and Maehly (1955) by measuring the decomposition of hydrogen peroxide $\left(\mathrm{H}_{2} \mathrm{O}_{2}\right)$ at $240 \mathrm{~nm}\left(\varepsilon=40 \mathrm{M}^{-1} \mathrm{~cm}^{-1}\right)$. The ascorbate peroxidase (APX) activity was determined according to the method described by Nakano and Asada (1981), based on the oxidation of ascorbate by $\mathrm{H}_{2} \mathrm{O}_{2}$ and decrease in absorption at $290 \mathrm{~nm}\left(\varepsilon=2.8 \mathrm{mM}^{-1} \mathrm{~cm}^{-1}\right)$.



\section{Statistical analysis}

Statistical analyses of the data weredone by the analysis of variance (ANOVA). The significant differences between the means of stress treatments were determined by the LSD (least significant difference) test at $p$ $<0.01$ by SPSS-20.0 (USA). Graphs were prepared using the Microsoft Excel program. Principal component analysis (PCA) was performed using XLSTAT software. The first two principal components were used to derive PCA-biplot, and the possible associations among the genotypes and measured physiological and biochemical traits were determined.

\section{RESULTS AND DISCUSSION}

Plant response to salinity stress is a complex phenomenon as it involves changes in morphology to change in metabolism. The changes depend on various factors such as stress level, tolerance potential of the plants, and developmental stage of plants.

\section{Physiological response of barley cultivars grown under different salt stress}

The responses of Indian barley cultivars Alfa93, DWRB73, DL88, NB1, NB3, and NDB1173 to salt stress-induced conditions assessed by comparing the shoot height and fresh weight of the plants are given in Fig. 1; Table 1 and 2.

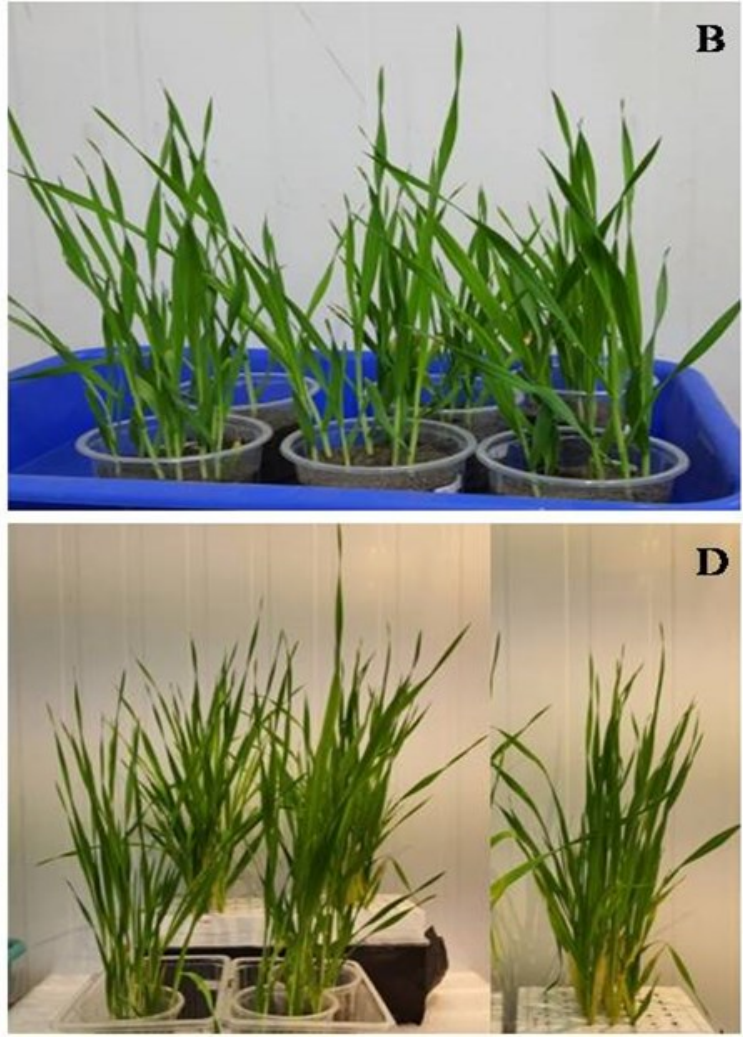

Fig. 1. Effect of salinity treatment on the growth of barley cultivars under (A) control (0 mM NaCl) and saline (B) 100

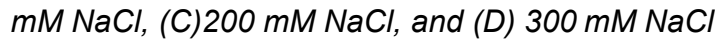


Table 1. Effects of salinity treatment on growth parameter shoot heigth $(\mathrm{cm})$ of Hordeum vulgare L. cultivars grown under control $(0 \mathrm{mM} \mathrm{NaCl})$ and saline $(100,200$, and $300 \mathrm{mM} \mathrm{NaCl})$ conditions. Values are means $\pm \mathrm{SD}(\mathrm{n}=3$ ). Asterisks $\left({ }^{*}\right)$ denote the mean differences are significant from controls at 0.01 level.

\begin{tabular}{lllllllll}
\hline & \multicolumn{3}{c}{ Shoot Height $(\mathbf{c m}) \mathbf{7}$ days } & \multicolumn{3}{c}{ Shoot Height (cm) 14 days } \\
\cline { 2 - 10 } & $\mathbf{0} \mathbf{~ m M ~ N a C l}$ & $\mathbf{1 0 0} \mathbf{~ m M}$ & $\mathbf{2 0 0} \mathbf{~ m M}$ & $\mathbf{3 0 0} \mathbf{~ m M}$ & $\mathbf{0 ~ m M ~ N a C l}$ & $\mathbf{1 0 0} \mathbf{~ m M}$ & $\mathbf{2 0 0} \mathbf{~ m M}$ & $\mathbf{3 0 0} \mathbf{~ m M}$ \\
& & $\mathbf{N a C l}$ & $\mathbf{N a C l}$ & $\mathbf{N a C l}$ & & $\mathbf{N a C l}$ & $\mathbf{~ N a C l}$ & $\mathbf{N a C l}$ \\
\hline Alfa 93 & $27.2 \pm 2.3$ & $26.8 \pm 1.6$ & $19.0 \pm 1.3^{*}$ & $17.5 \pm 2.1^{*}$ & $30.3 \pm 2.2$ & $28.9 \pm 3.8$ & $23.8 \pm 2.0^{*}$ & $21.3 \pm 1.4^{*}$ \\
DWRB73 & $35.0 \pm 1.8$ & $35.2 \pm 1.9$ & $31.8 \pm 2.7$ & $29.8 \pm 1.3^{*}$ & $39.9 \pm 1.8$ & $37.9 \pm 1.4$ & $36.7 \pm 1.5$ & $31.1 \pm 1.5^{*}$ \\
DL88 & $28.9 \pm 3.1$ & $27.9 \pm 3.2$ & $26.6 \pm 2.8$ & $22.4 \pm 1.6$ & $31.8 \pm 2.2$ & $30.0 \pm 1.8$ & $28.9 \pm 1.4$ & $25.1 \pm 1.5^{*}$ \\
NB3 & $33.7 \pm 1.7$ & $32.3 \pm 2.2$ & $29.8 \pm 2.3$ & $24.7 \pm 1.3^{*}$ & $38.1 \pm 2.2$ & $36.7 \pm 1.5$ & $31.6 \pm 1.5^{*}$ & $25.8 \pm 1.3^{*}$ \\
NDB 1173 & $27.2 \pm 3.1$ & $28.6 \pm 1.3$ & $26.5 \pm 2.1$ & $24.2 \pm 1.5$ & $31.9 \pm 1.4$ & $31.7 \pm 1.6$ & $28.9 \pm 1.2$ & $25.8 \pm 2.2^{*}$ \\
NB1 & $29.5 \pm 2.6$ & $28.6 \pm 1.6$ & $27.0 \pm 2.1$ & $26.3 \pm 2.1$ & $31.4 \pm 1.6$ & $28.1 \pm 1.3$ & $24.4 \pm 1.8^{*}$ & $23.7 \pm 2.0^{*}$ \\
\hline
\end{tabular}
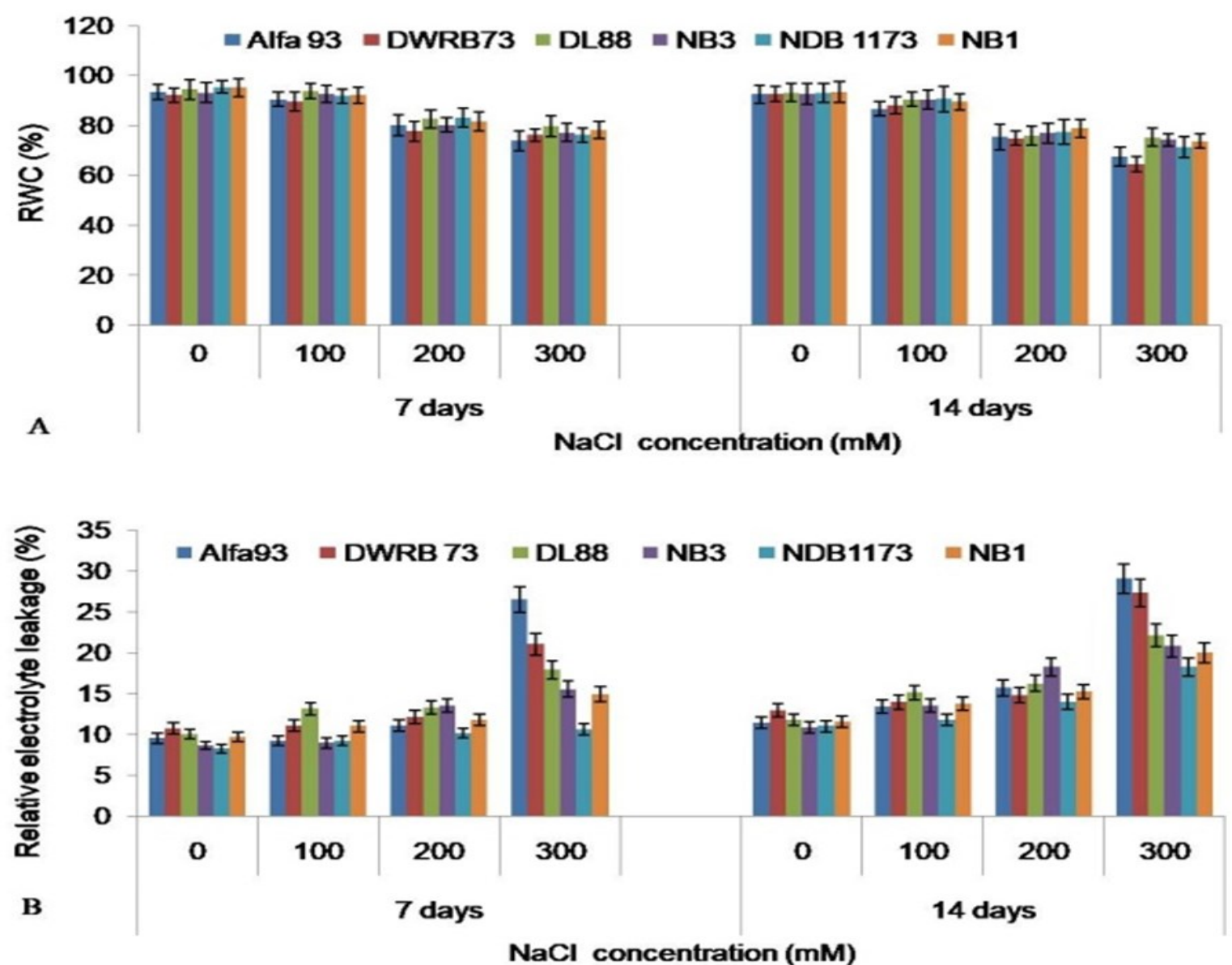

Fig. 2. Different physiological responses of plants under salinity stress treatment (A) Relative Water Content (RWC\%), and (B) Relative Electrolyte leakage in leaves of barley cultivars under control and saline (0 mM, $100 \mathrm{mM}, 200 \mathrm{mM}$, and $300 \mathrm{mM} \mathrm{NaCl}$ ) conditions after 7 days and 14 days.

\section{Relative water content (RWC \%)}

Leaf RWC of barley cultivars under control and salinitystressed conditions for 7 days and 14 days ranged from $95.3 \%$ to $73.8 \%$ and $93.2 \%$ to $64.4 \%$, respectively (Fig. 2A). When salinity stress increased, the RWC of the plants decreased. The most reduction in RWC of 7 days was observed in susceptible lines than tolerant varieties. In control plants (both SS and ST), there were no significant differences in RWC, whereas, at $300 \mathrm{mM}$ salinity stress level, a steep decline was observed in SS plants. In the susceptible barley lines, Alfa93, and DWRB73 lines at $300 \mathrm{mM}$, RWC was $78.8 \%$ and $76.1 \%$ after 7 days, and after 14 days, it was decreased to $67.4 \%$ and $64.4 \%$, respectively. In the tolerant barley lines at $300 \mathrm{mM}$ stress level, DL88 exhibits $79.8 \%$ after 7 days and $75.2 \%$ after 14 days, and a similar pattern 




\section{Relative electrolyte leakage}

Electrolyte leakage can be used as an indicator for membrane damage caused by abiotic stresses on the membrane. Electrolyte leakage was analyzed under salinity stress-induced conditions. The relative percent electrolyte leakage was higher in treated plants than in control plants (Fig. 2B). No significant change was observed in control plants, whether salinity tolerant or susceptible but observed at $300 \mathrm{mM}$ significant difference between them. Tolerant lines exhibited decreased electrolyte leakage than susceptible lines, in 7 days, susceptible lines Alfa93, DWRB73 showed 26.0 and 20.6 percent relative electrolyte leakage, respectively, whereas tolerant lines DL88, NB1, NB3, and NDB1173 exhibits 17.6, 14.6, 15.3, and 10.4 percent relative electrolyte leakage respectively, a similar pattern of relative electrolyte leakage was also observed after 14 days treatment.

Salinity stress may modify the physical structure of the plasma membrane by a change in chemical composition and organic acids (Bajji et al., 2001). The membrane injury depends on the level of osmotic stress and the duration (Kocheva et al., 2004). Electrolyte leakage gradually increases when salt stress levels increase, and the level of this leakage depends on cultivars, such as salt-tolerant cultivars with lower electrolyte leakage than susceptible cultivars (Mahlooji et al., 2018; Zeeshan et al., 2020). In the present study, electrolyte leak- 
age in salinity susceptible lines Alfa93, DWRB73 were higher in comparison to the salinity tolerant lines DL88, NB1, NB3, and NDB1173. A similar result was also reported by Mahlooji et al. (2018), who reported salt susceptible barley line Morocco exhibited higher electrolyte leakage than salt-tolerant line Khatam under salinity stress conditions. When comparing the electrolyte leakage in control and $300 \mathrm{mM} \mathrm{NaCl}$ treated barley cultivar CM72, wheat cultivars Suntop (ST) and Sunmat (SS) higher value of electrolyte leakage was observed in $300 \mathrm{mM} \mathrm{NaCl}$ treated plants (Zeeshan et al., 2020). Elsawy et al. (2018) studied the effects of salt stress in two Egyptian barley cultivars, Giza 126 (SS) and Giza 128 (ST). They reported that stress exhibited higher electrolyte leakage than control plants; also, tolerant lines had reduced electrolyte leakage than susceptible lines under salt stress-induced conditions $(200 \mathrm{mM}$ $\mathrm{NaCl}$ ). Electrolyte leakage may be an important tool in the screening of salt susceptible and tolerant cultivars.

\section{Effect of salt stress on photosynthetic pigment}

Salinity stress negatively affected the photosynthetic pigments and an increase in salinity stress caused loss of photosynthetic pigments. However, among cereal crops, barley is somewhat salt tolerant. Changes in photosynthetic pigments are shown in Fig. 3. The highest loss of photosynthetic pigments, Chl-a, was recorded in salt susceptible lines and was $49.5 \%$ and $59.5 \%$ in Alfa93 in 7 and 14 days respectively under $300 \mathrm{mM}$ salt stress level, while another susceptible line, DWRB73, exhibits loss of $52.1 \%$ and $64 \%$ in 7 and 14 days respectively. In comparison to susceptible lines, tolerant lines showed less loss of photosynthetic pigments. Among tolerant lines under $300 \mathrm{mM}$ salt stress, NB1 showed less loss in Chl-a in 7 days, while in 14 days, NDB1173 was showed less loss in Chl-a. The loss in Chl-b under $300 \mathrm{mM}$ salt stress was 54.7 and $62.2 \%$ in 7days in Alfa93 and DWRB73, respectively, while in salt-tolerant lines, loss in Chl-b was higher than susceptible lines 14 days. A similar pattern like Chl-a in CRT was also observed. Susceptible lines lose more carotenoids pigment than tolerant lines.

Chlorophylls are fundamental pigments in plants to absorb light and release electrons. However, various types of chlorophyll exist in plants, but only two types are possessed by the terrestrial plants: Chl-a and Chlb. These two pigments form light-harvesting complexes, which absorb the most light (Kume et al., 2018). Carotenoid is the part of the photosystem and chlorophylls and is located in chromoplasts (Costache et al., 2012).

\section{Antioxidant enzyme activities}

The antioxidant enzyme activities of the six barley cultivars under control and salinity-stressed conditions are shown in Fig. 3. The SOD levels under control condi- tions were lower than stressed levels for both 7 days and 14 days. SOD activity was significantly lower in Alfa93 and DWRB73 than in the DL88, NB1, NB3, and NDB1173 barley lines (Fig. 4). Salinity had variable effects on SOD activity in all tolerant and susceptible cultivars.Salt tolerant lines demonstrate an increasing trend of SOD activity along with susceptible lines but different activity levels. Susceptible lines Alfa93 and DWRB73 under $300 \mathrm{mM}$ salinity stress showed an increase of $85 \%$ and $79 \%$ in 7 days, and $96 \%$ and $108 \%$ in 14 days respectively in comparison to control. Among salt-tolerant lines, NB3 had shown the highest activity under $300 \mathrm{mM}$ salt stress than control, 110\% activity in 7 days, and $140 \%$ activity in 14 days. APX activity increased with an increase in salinity stress. After 7 days of treatment,a $60 \%$ increase in activity was observed in tolerant line NDB1173 and then NB1, in which activity was increased to $46.2 \%$. After 14 days,Alfa93 and DWRB73 exhibit $76 \%$ and $36.9 \%$ increase in APX activity, whereas NDB1173 exhibits $100.5 \%$ increased activity. At $300 \mathrm{mM} \mathrm{NaCl}, \mathrm{CAT}$ activity is $91 \%$ and $50.3 \%$ higher in DWRB73 and Alfa93 than in control plants. However, NB1 showed the highest $83.4 \%$ increase in CAT activity in $300 \mathrm{mM} \mathrm{NaCl}$ treated plants in salt-tolerant lines. Salinity stress increases the POX activity also; salt-tolerant lines exhibit more POD activity than susceptible lines. After 14 days, salt-tolerant lines DL 88, NB1, NB3, and NDB173, exhibits POD activity were recorded $39.3 \%, 65.8 \%$, $42.7 \%$, and $33.7 \%$ respectively under $300 \mathrm{mM} \mathrm{NaCl}$ treatment than control plants after 14 days.

Salinity stress induces ROS accumulation in plants, affecting membrane integrity and other cellular components that resulted in reduced growth and development (Tuna et al., 2007). However, plant defence systems readily mitigate the salinity-induced $R O S$ by enhanced antioxidants such as SOD, POD, CAT, and APX (Noreen et al., 2021).

APX activity increased by $76 \%$ and $36.9 \%$ in Alfa93 and DWRB73 after 14 days of salt treatment, whereas in NDB1173 (ST) increase in activity was $100.5 \%$. CAT activity in DWRB73 and Alfa93 was $91 \%$ and $50.3 \%$ higher than the control plants at $300 \mathrm{mM}$ salinity stress. The results of CAT activity in leaves of salinity susceptible cultivars Alfa93 and DWRB73 of the present study are in disagreement with the result of Elsawy et al. (2018), they reported no significant difference in CAT activity in leaves of control and salt-treated barley cultivar Giza 126. In line with our results, Abdel Latef et al. (2019) reported a gradual increase in POD, CAT, and APX in two Egyptian wheat cultivars, Gemmiza 11 (SS), Misr 1 (ST), when salinity stress increases. CAT activity was high in salt-sensitive cultivar Gemmiza 11 under salinity stress, while POD and APX were higher in tolerant cultivar Misr1. Two contrasting Egyptian wheat cultivars, Sakha 95 and Misr 2, exhibit high activ- 


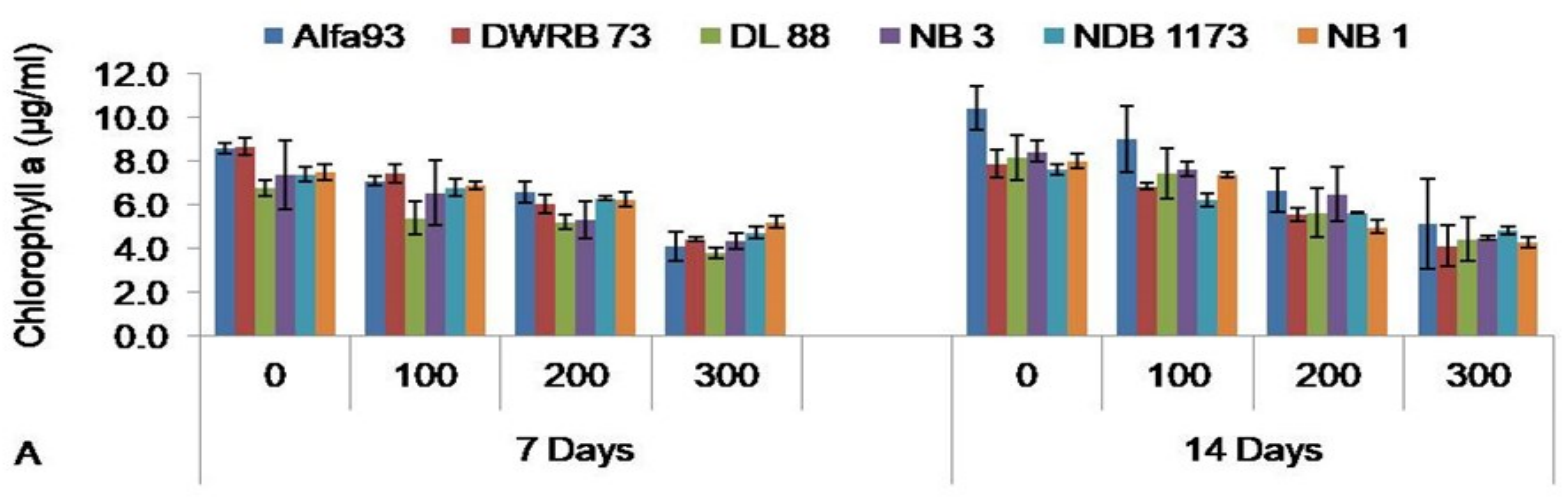

$\mathrm{NaCl}$ concentration $(\mathrm{mM})$

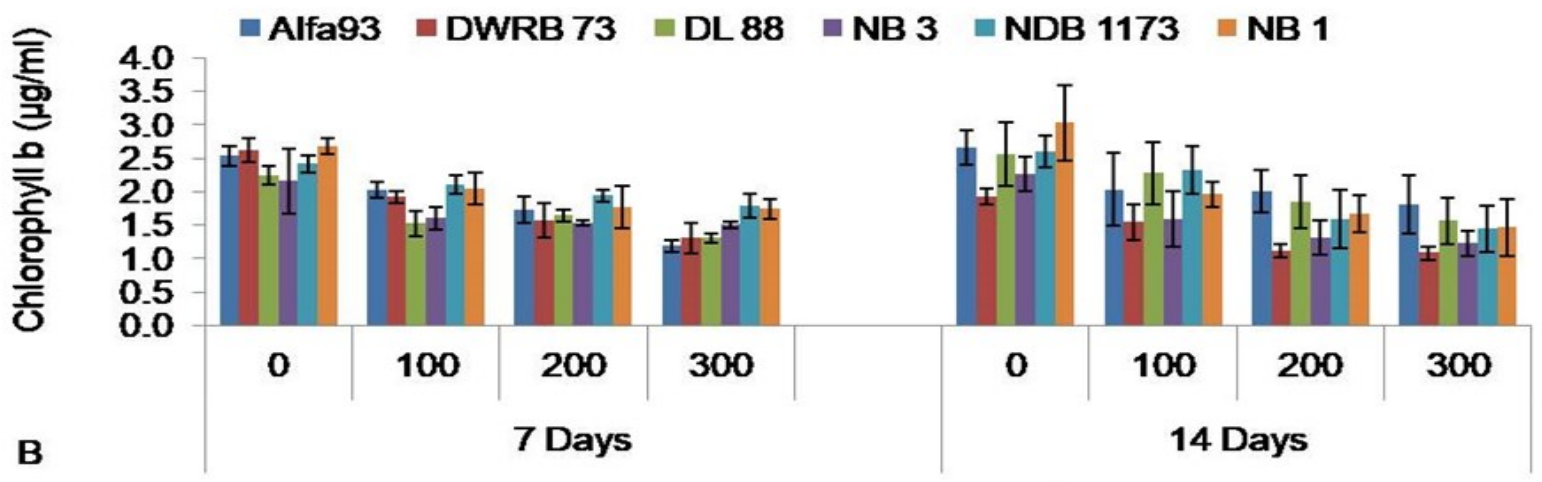

$\mathrm{NaCl}$ concentration $(\mathrm{mM})$

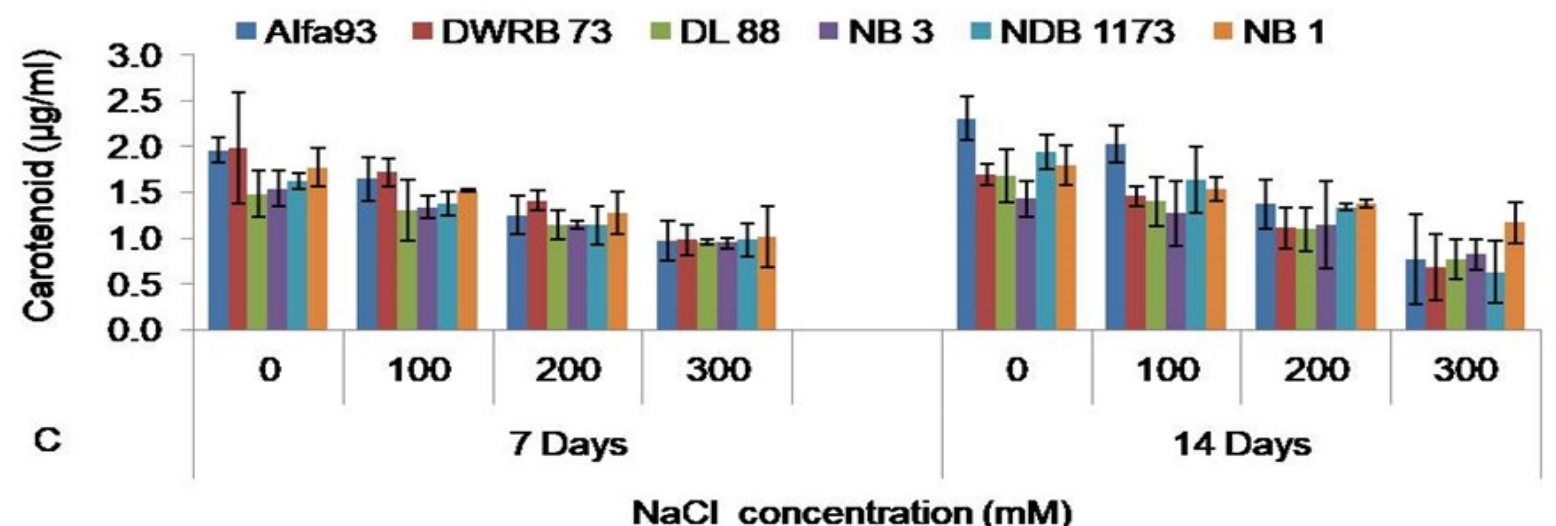

Fig. 3. The effect of salinity stress treatment on photosynthetic pigments (A) Chlorophyll a (B) Chlorophyll $b$ and (C) Carotenoid in leaves of barley cultivars under control and saline $(0 \mathrm{mM}, 100 \mathrm{mM}, 200 \mathrm{mM}$, and $300 \mathrm{mM} \mathrm{NaCl}) \mathrm{conditions}$ after 7 days and 14 days.

ity of antioxidant enzymes under salinity stress of 150 $\mathrm{mM} \mathrm{NaCl}$ than control plants (Yassin et al., 2019). In the present study, the enzymatic activities of the salttolerant lines DL88, NB1, NB3, and NDB1173 were higher in salinity-treated plants than in control plants. Also, similar pattern was found in susceptible lines Alfa93 and DWRB73. When comparing the enzymatic activities between tolerant and susceptible lines SOD, POD, APX were high in tolerant lines. However, CAT activity was recorded high in susceptible lines Alfa93 and DWRB73.
Principal component analysis of physiological parameters

Principal component analysis of the studied physiological parameters studied under salt-stressed conditions was done for the barley genotypes. All parameters were loaded into two major principal components (F1 and F2), which described the cumulative variance of 78.6, 78.8, 86.4, and 79.7\% in control, $100 \mathrm{mM}, 200$ $\mathrm{mM}$, and $300 \mathrm{mM}$, respectively, after 7 days of salt treatment. Similarly, the cumulative variance after 14 days were $69.4,69.5,66.5$, and $80.0 \%$ in control, 100 



$\mathrm{NaCl}$ concentration (mM)

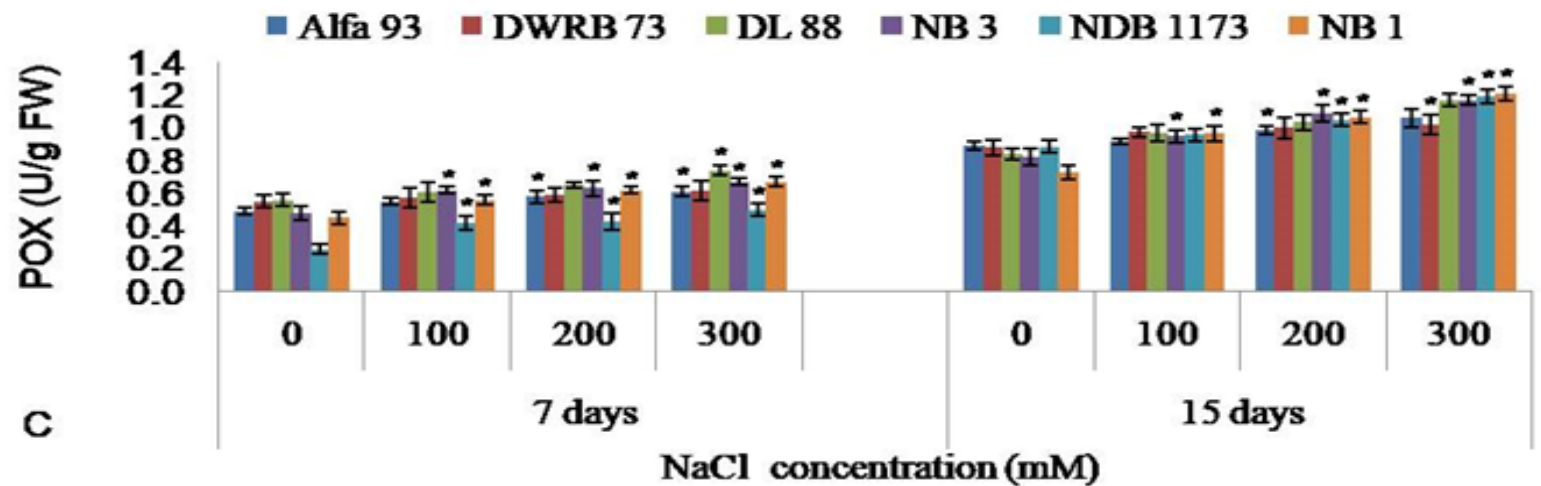

$\mathrm{NaCl}$ concentration $(\mathrm{mM})$

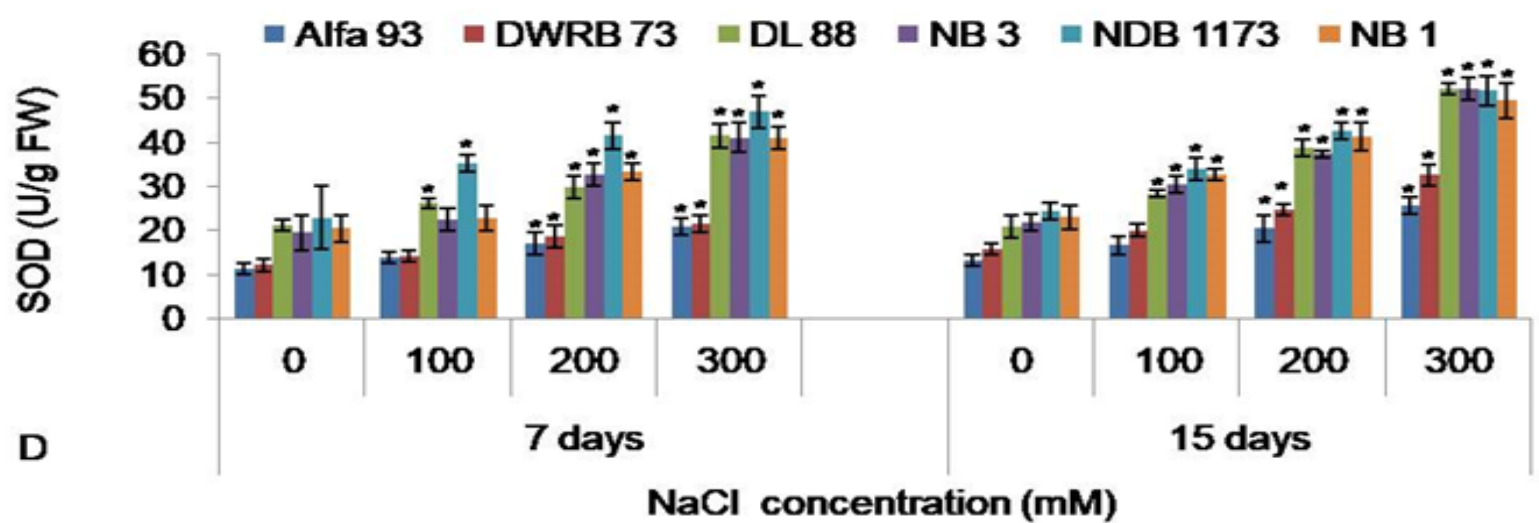

Fig. 4. Effect of salinity stress treatment on $(A) C A T,(B) A P X,(C) P O X$, and (D) SOD activities in leaves of barley cultivars under control and saline (0 mM, $100 \mathrm{mM}, 200 \mathrm{mM}$, and $300 \mathrm{mM} \mathrm{NaCl})$ conditions after 7 days and 14 days. Values are mean $\pm S D$ of three replicates, and asterisks denote significant differences from controls $(P<0.01)$ 
$\mathrm{mM}, 200 \mathrm{mM}$, and $300 \mathrm{mM}$, respectively. After 7 days of treatment, PC1 accounted for $57.7 \%$ of the variation in the PCA plot of controls and was positively correlated with RWC and SOD. However, photosynthetic pigments (Chl-a, Chl-b, and CRT), REL, and antioxidant enzymes except SOD were negatively correlated. PC2 accounted for $20.9 \%$ of the variation and was positively affected by photosynthetic pigments (Chl-a, Chl-b, and CRT), REL, and RWC but negatively affected by the antioxidant enzymes. Upon comparing the PCs of control and $300 \mathrm{mM}, \mathrm{NaCl}$ treated samples of 7 days and 14 days, a cumulative variance of control was $78.6 \%$ and 69.4 respectively, whereas, $300 \mathrm{mM} \mathrm{NaCl}$ treated sample was $79.8 \%$ and $80.0 \%$, respectively (Table 3 , Fig. 5 and 6 ).

The PCA also demonstrated the different responses of barley genotypes under salt stress conditions. The biplot analysis signifies that the antioxidant enzyme SOD and APX were positively associated with NB1 and NDB1173, POX and CAT associated with DL88 and NB3 in $300 \mathrm{mM}$ salt-treated plants for 7 days. When analyzed, the biplot of 14 days salt-treated plants POX and SOD were associated with NDB1173, APX, and CAT was associated with Alfa93. According to Guellim et al. (2020), genotype position from the centroid described the tolerance of plants to the stress, least the distance more the tolerance. The present study showed that the centroid position of Alfa93 and DWRB73 was at a distant position thanNB1, NDB1173, NB3, and DL88 in 14 days salt-stressed plants. Barley genotypes were ranked according to their tolerance level after 14 days of salinity treatment DL88 was the most tolerant than NB3, NB1, and NDB1173, least tolerant was DWRB73.

The principal component analysis enabled recognizing the physiological traits associated with the salinity stress and representing the level of salt stress tolerance among the genotypes.In the present study, antioxidant enzymes activity under salt stress and other physiological parameters such as REL, RWC, and photosynthetic pigments positively correlated with the tolerant genotypes. The result of the present study is also in agreement with the results of Ahmadi et al. (2020) who evaluated the physiological and biochemical response of wheat genotypes. PC analysis revealed the and tolerant genotypes exhibit enhanced responses to salinity stress.

Pour-Aboughadareh et al. (2020) reported that the antioxidant enzyme activity was positively correlated with the stress tolerance of the plant. In the present study, antioxidant enzyme activity was increased when barley plants were subjected to salinity stress. Higher activity was observed in tolerant lines than susceptible lines except for CAT activity. This enhanced enzyme activity may be used as a marker for screening of the salinity tolerance in the plants.

\section{Conclusion}

This study indicated the effects of 7 days and 14 days prolonged salinity stress on barley plants (Alfa93, DWRB73, DL88, NB1, NB3, NDB1173) and their impact on physiology like decreased growth, loss in biomass, changes in photosynthetic pigments, and biochemical activities like antioxidant enzymes activity. The findings illustrated salinity stress, stress level, reduced growth, photosynthetic pigments, and antioxidant enzyme activity. Therefore, the elevated activity of antioxidant enzymes in salinity-stressed barley plants may be the mechanism of plants to tolerate the stress. The antioxidant enzyme (SOD) initiated the antioxidative process, which the CAT, POD followed. Plant's response in the form of changes in physiological as well as biochemical activity suggested that the strategies were adopted by the plants to mitigate stress. Exploiting these characteristics of the plants in the screening of tolerant and susceptible lines incorporates them in selecting lines for cultivation in salt-affected areas.

Table 3. Eigenvalues, variability (\%), and cumulative (\%) of PC1 (F1) and PC2 (F2) axes of PCA of physiological parameters.

\begin{tabular}{|c|c|c|c|c|c|c|c|c|c|}
\hline & \multicolumn{2}{|c|}{ OmM NaCl } & \multicolumn{2}{|c|}{$100 \mathrm{mM} \mathrm{NaCl}$} & \multicolumn{2}{|c|}{$200 \mathrm{mM} \mathrm{NaCl}$} & \multicolumn{2}{|c|}{$300 \mathrm{mM} \mathrm{NaCl}$} & \multirow{5}{*}{14 Days } \\
\hline & F1 & F2 & F1 & F2 & F1 & F2 & F1 & F2 & \\
\hline Eigen value & 3.829 & 2.413 & 4.063 & 2.192 & 3.686 & 2.295 & 4.821 & 2.381 & \\
\hline Variability (\%) & 42.549 & 26.810 & 45.141 & 24.356 & 40.960 & 25.497 & 53.571 & 26.453 & \\
\hline Cumulative \% & & 69.360 & & 69.497 & & 66.456 & & 80.025 & \\
\hline Eigen value & 5.192 & 1.885 & 4.127 & 2.962 & 4.803 & 2.969 & 4.565 & 2.612 & \\
\hline Variability (\%) & 57.692 & 20.940 & 45.858 & 32.908 & 53.370 & 32.984 & 50.718 & 29.027 & 07 Days \\
\hline Cumulative \% & & 78.632 & & 78.766 & & 86.354 & & 79.745 & \\
\hline
\end{tabular}




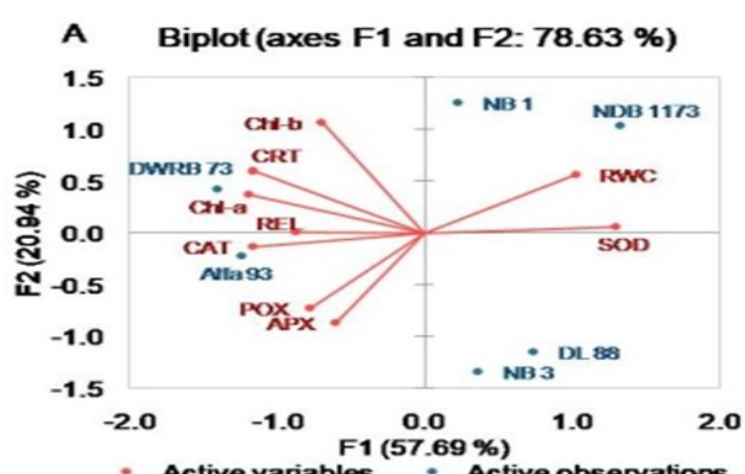

- Active variables

C

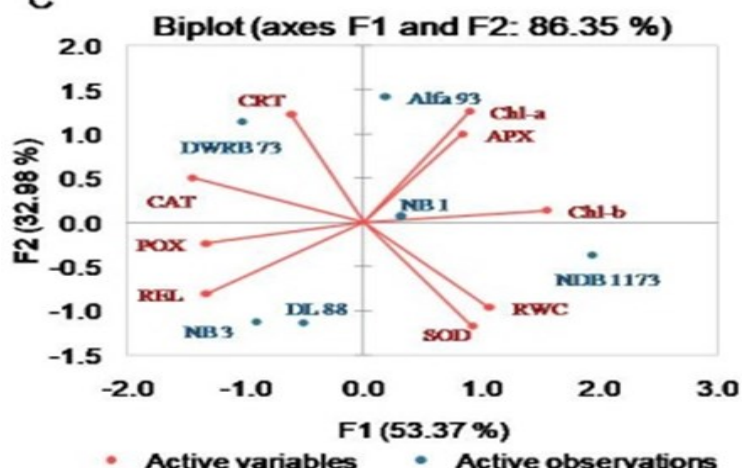

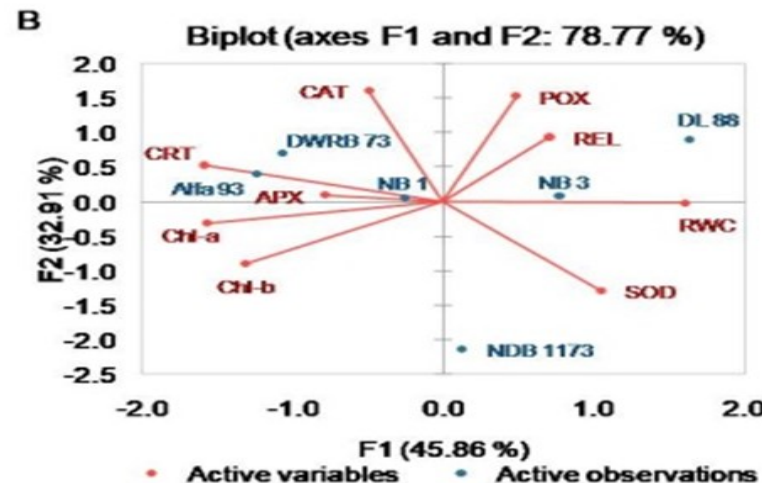

D

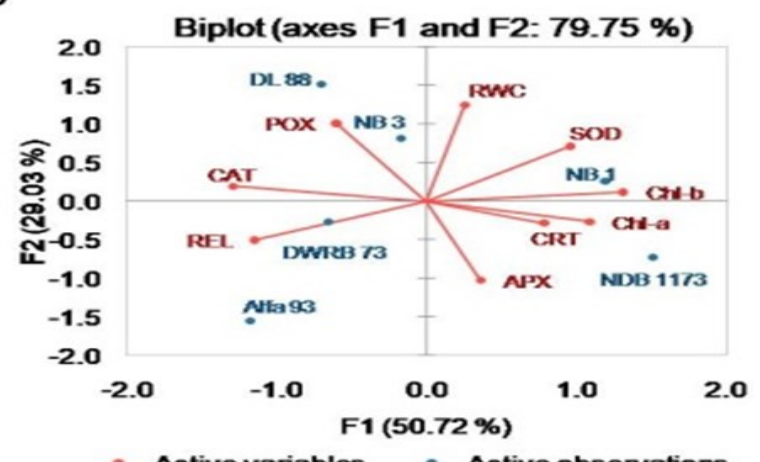

Fig. 5. Principle Component Analysis (PCA) Biplots of 7 days salt stress treated samples (A) Control, (B) $100 \mathrm{mM} \mathrm{NaCl}$, (C) $200 \mathrm{mM} \mathrm{NaCl}$, (D) $300 \mathrm{mM} \mathrm{NaCl}$.

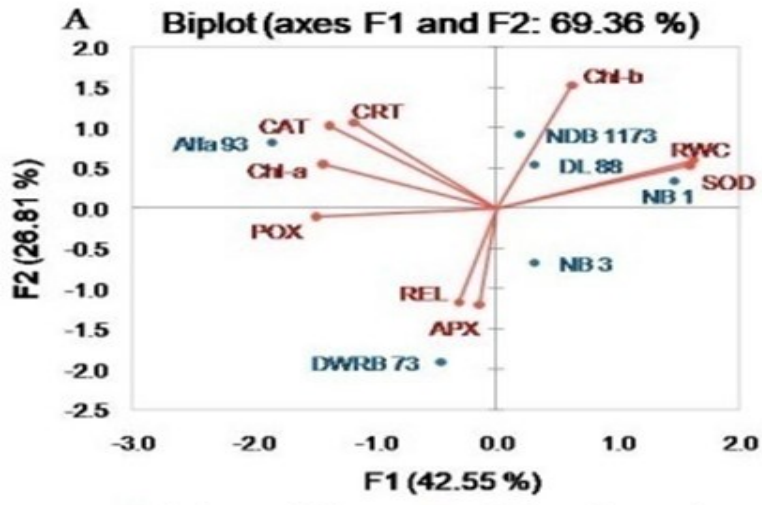

- Active variables - Active observations

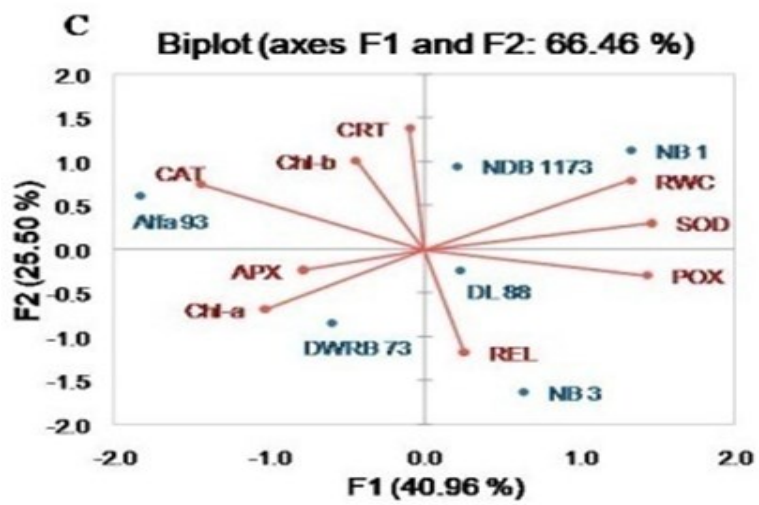

- Active variables - Active observations

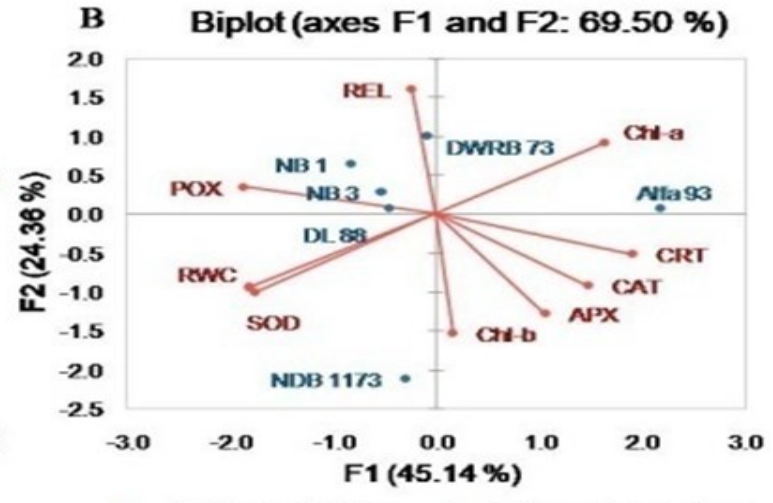

- Active variables - Active observations

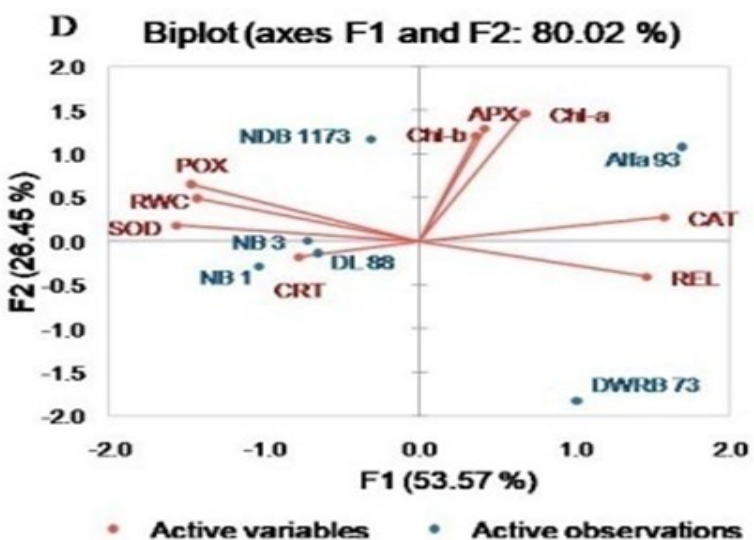

Fig. 6. Principle component analysis (PCA) Biplots of 14 days salt stress treated samples (A) Control, (B) $100 \mathrm{mM} \mathrm{NaCl}$, (C) $200 \mathrm{mM} \mathrm{NaCl}$, (D) $300 \mathrm{mM} \mathrm{NaCl}$. 
Sharma, J. K. et al. / J. Appl. \& Nat. Sci. 13(3), 1020 - 1031 (2021)

\section{ACKNOWLEDGEMENTS}

The grant no. SB/YS/LS-334/2013 and SB/EMEQ085/2014 by Science and Engineering Research Board (SERB), New Delhi, India and grant no. 41-515/2012 (SR) by the University Grants Commission, New Delhi, India to Nater Pal Singh and University Research Scholarship to Jitendra Kumar Sharma from Maharshi Dayanand University is highly acknowledged.

\section{Conflict of interest}

The authors declare that they have no conflict of interest.

\section{REFERENCES}

1. Abdel Latef, A. A. H., Kordrostami, M., Zakir, A., Zaki, H.\&Saleh, O. M. (2019). Eustress with H2O2 facilitates plant growth by improving tolerance to salt stress in two wheat cultivars. Plants, 8(9), 303. https://dx.doi.org/1 $0.3390 \% 2 F$ plants 8090303

2. Ahmadi, J., Pour-Aboughadareh, A., Ourang, S. F., Khalili, P.\&Poczai, P. (2020). Unraveling salinity stress responses in ancestral and neglected wheat species at early growth stage: A baseline for utilization in future wheat improvement programs. Physiology and Molecular Biology of Plants, 26(3), 537-549. https://doi.org/10.1007/s12298020-00768-4

3. Arif, Y., Singh, P., Siddiqui, H., Bajguz, A., \& Hayat, S (2020). Salinity induced physiological and biochemical changes in plants: An omic approach towards salt stress tolerance. Plant Physiology and Biochemistry, 156, 64-77. https://doi.org/10.1016/j.plaphy.2020.08.042

4. Bajji, M., Kinet, J.-M.\& Lutts, S. (2001). The use of the electrolyte leakage method for assessing cell membrane stability as a water stress tolerance test in durum wheat. Plant Growth Regulation, 36(1), 61-70. https:// doi.org/10.1023/A:1014732714549

5. Barrs, H. D.\& Weatherley, P. E. (1962). A re-examination of the relative turgidity technique for estimating water deficits in leaves. Australian Journal of Biological Sciences, 15(3), 413-428. https://doi.org/10.1071/BI9620413

6. Bera, S., Sabikhi, L., \& Singh, A. K. (2018). Assessment of malting characteristics of different Indian barley cultivars. Journal of Food Science and Technology, 55(2), 704 -711. https://doi.org/10.1007/s13197-017-2981-1

7. Chance, B.\&Maehly, A. C. (1955). Assay of catalases and peroxidases. https://doi.org/10.1016/S0076-6879(55)0230 0-8

8. Costache, M. A., Campeanu, G.\& Neata, G. (2012). Studies concerning the extraction of chlorophyll and total carotenoids from vegetables. Romanian Biotechnological Letters, 17(5), 7702-7708.

9. Dhindsa, R. S., Plumb-Dhindsa, P.\& Thorpe, T. A. (1981). Leaf senescence: Correlated with increased levels of membrane permeability and lipid peroxidation, and decreased levels of superoxide dismutase and catalase. Journal of Experimental Botany, 32(1), 93-101. https:// doi.org/10.1093/jxb/32.1.93

10. Elsawy, H. I., Mekawy, A. M. M., Elhity, M. A., Abdel-
Dayem, S. M., Abdelaziz, M. N., Assaha, D. V., Ueda, A.\&Saneoka, H. (2018). Differential responses of two Egyptian barley (Hordeum vulgare L.) cultivars to salt stress. Plant Physiology and Biochemistry, 127, 425-435. https://doi.org/10.1016/j.plaphy.2018.04.012

11. González, L.\& González-Vilar, M. (2001). Determination of relative water content. In: Handbook of plant ecophysiology techniques (pp. 207-212). Springer, Dordrecht.

12. Guellim, A., Hirel, B., Chabrerie, O., Catterou, M., Tetu, T., Dubois, F., Ahmed, H. B.\&Kichey, T. (2020). Screening for durum wheat (Triticum durum Desf.) cultivar resistance to drought stress using an integrated physiological approach. Journal of Crop Science and Biotechnology, 23, 355-365. https://doi.org/10.1007/s12892-020-00043-8

13. Kocheva, K., Lambrev, P., Georgiev, G., Goltsev, V.\&Karabaliev, M. (2004). Evaluation of chlorophyll fluorescence and membrane injury in the leaves of barley cultivars under osmotic stress. Bioelectrochemistry, 63(12), 121-124. https://doi.org/10.1016/j.bioelechem.200 3.0 9.020

14. Kumar, P., \& Sharma, P. K. (2020). Soil salinity and food Security in India. Frontiers in Sustainable Food Systems, 4, 174. https://doi.org/10.3389/fsufs.2020.533781

15. Kume, A., Akitsu, T.\&Nasahara, K. N. (2018). Why is chlorophyll b only used in light-harvesting systems? Journal of Plant Research, 131(6), 961-972. https://doi.org/10.1007/ s10265-018-1052-7

16. Lakra, N., Nutan, K. K., Das, P., Anwar, K., Singla-Pareek, S. L.\& Pareek, A. (2015). A nuclear-localized histonegene binding protein from rice (OsHBP1b) functions in salinity and drought stress tolerance by maintaining chlorophyll content and improving the antioxidant machinery. Journal of Plant Physiology, 176, 36-46. https:// doi.org/10.1016/j.jplph.2014.11.005

17. Mahlooji, M., Sharifi, R. S., Razmjoo, J., Sabzalian, M. R.\& Sedghi, M. (2018). Effect of salt stress on photosynthesis and physiological parameters of three contrasting barley genotypes. Photosynthetica, 56(2), 549-556. https://doi.org/10.1007/s11099-017-0699-y

18. Minocha, R., Martinez, G., Lyons, B.\& Long, S. (2009) Development of a standardized methodology for quantifying total chlorophyll and carotenoids from foliage of hardwood and conifer tree species. Canadian Journal of Forest Research, 39(4), 849-861. https://doi.org/10.1139/X09 $-015$

19. Moradi, M., Dehghani, H., \& Ravari, S. Z. (2021). Genetics of physiological and agronomical traits linked to salinity tolerance in tomato. Crop and Pasture Science, 72(4), 280 -290. https://doi.org/10.1071/CP20394

20. Naeem, M., Mehboob, N., Farooq, M., Farooq, S., Hussain, S., M Ali, H., \& Hussain, M. (2021). Impact of different barley-based cropping systems on soil physicochemical properties and barley growth under conventional and conservation tillage systems. Agronomy, 11(1), 8. https://doi.org/doi.org/10.3390/agronomy11010008

21. Nakano, Y.\& Asada, K. (1981). Hydrogen peroxide is scavenged by ascorbate-specific peroxidase in spinach chloroplasts. Plant and Cell Physiology, 22(5), 867-880. https://doi.org/10.1093/oxfordjournals.pcp.a076232

22. Noreen, S., Sultan, M., Akhter, M. S., Shah, K. H., Ummara, U., Manzoor, H., Ulfat, M., Alyemeni, M. N.\& Ahmad, P. (2021). Foliar fertigation of ascorbic acid and zinc im- 
proves growth, antioxidant enzyme activity and harvest index in barley (Hordeum vulgare L.) grown under salt stress. Plant Physiology and Biochemistry, 158, 244-254. https://doi.org/10.1016/j.plaphy.2020.11.007

23. Ortiz, A. C., \& Jin, L. (2021). Chemical and hydrological controls on salt accumulation in irrigated soils of southwestern US. Geoderma, 391, 114976. https:// doi.org/10.1016/j.geoderma.2021.114976

24. Pour-Aboughadareh, A., Etminan, A., Abdelrahman, M., Siddique, K. H.\& Tran, L.-S. P. (2020). Assessment of biochemical and physiological parameters of durum wheat genotypes at the seedling stage during polyethylene glycol-induced water stress. Plant Growth Regulation, 92(1), 81-93. https://doi.org/10.1007/s10725-020-00621-4

25. Soni, S., Kumar, A., Sehrawat, N., Kumar, A., Kumar, N., Lata, C.\& Mann, A. (2021). Effect of saline irrigation on plant water traits, photosynthesis and ionic balance in durum wheat genotypes. Saudi Journal of Biological Sciences, 28(4), 2510-2517. https://doi.org/10.1016/j.sjbs.20 21.01.052

26. Tanou, G., Molassiotis, A.\& Diamantidis, G. (2009). Induction of reactive oxygen species and necrotic death-like destruction in strawberry leaves by salinity. Environmental and Experimental Botany, 65(2-3), 270-281. https:// doi.org/10.1016/j.envexpbot.2008.09.005

27. Tuna, A. L., Kaya, C., Ashraf, M., Altunlu, H., Yokas, I.\& Yagmur, B. (2007). The effects of calcium sulphate on growth, membrane stability and nutrient uptake of tomato plants grown under salt stress. Environmental and Experimental Botany, 59(2), 173-178. https://doi.org/10.1016/ j.envexpbot.2005.12.007

28. Wellburn, A. R. (1994). The spectral determination of chlorophylls $a$ and $b$, as well as total carotenoids, using various solvents with spectrophotometers of different resolution. Journal of Plant Physiology, 144(3), 307-313. https:// doi.org/10.1016/S0176-1617(11)81192-2

29. Xie, Y.-J., Xu, S., Han, B., Wu, M.-Z., Yuan, X.-X., Han, Y., Gu, Q., Xu, D.-K., Yang, Q.\& Shen, W.-B. (2011). Evidence of Arabidopsis salt acclimation induced by upregulation of $\mathrm{HY} 1$ and the regulatory role of RbohDderived reactive oxygen species synthesis. The Plant Journal, 66(2), 280-292. https://doi.org/10.1111/j.1365313x.2011.04488.x

30. Yassin, M., El Sabagh, A., Mekawy, A. M. M., Islam, M. S., Hossain, A., Barutcular, C., Alharby, H., Bamagoos, A., Liu, L.\& Ueda, A. (2019). Comparative performance of two bread wheat (Triticum aestivumL.) genotypes under salinity stress. Appl. Ecol. Environ. Res, 17, 5029-5041. http://dx.doi.org/10.15666/aeer/1702_50295041

31. Zeeshan, M., Lu, M., Sehar, S., Holford, P.\& Wu, F. (2020). Comparison of biochemical, anatomical, morphological, and physiological responses to salinity stress in wheat and barley genotypes deferring in salinity tolerance. Agronomy, 10(1), 127. https://doi.org/10.3390/agronomy 10010127

32. Zhu, J., Fan, Y., Shabala, S., Li, C., Lv, C., Guo, B., Xu, R.\& Zhou, M. (2020). Understanding mechanisms of salinity tolerance in barley by proteomic and biochemical analysis of near -isogenic lines. International Journal of Molecular Sciences, 21(4), 1516. https://doi.org/10.3390/ijms21 041516 